\title{
Stimulation of morphofunctional repair of the facial nerve with photobiomodulation, using the end-to-side technique or a new heterologous
}

\section{fibrin sealant}

\author{
Marcelie Priscila de Oliveira Rosso ${ }^{\mathrm{a}, *}$, Geraldo Marco Rosa Júnior ${ }^{\mathrm{b}}$, Daniela Vieira Buchaim ${ }^{\mathrm{c}}$, \\ Iris Jasmin Santos German ${ }^{a}$, Karina Torres Pomini ${ }^{a}$, Rafael Gomes de Souza ${ }^{c}$, Mizael Pereira ${ }^{a}$, \\ Idvaldo Aparecido Favaretto Júnior ${ }^{\mathrm{a}}$, Cleuber Rodrigo de Souza Bueno ${ }^{\mathrm{b}}$, \\ Jéssica Barbosa de Oliveira Gonçalves ${ }^{c}$, Rui Seabra Ferreira Júnior ${ }^{\mathrm{d}}$, Benedito Barraviera ${ }^{\mathrm{d}}$, \\ Jesus Carlos Andreo ${ }^{\mathrm{a}}$, Rogério Leone Buchaim ${ }^{\mathrm{a}, \mathrm{c}}$ \\ a Department of Biological Sciences (Anatomy), Bauru School of Dentistry, University of São Paulo (USP), Bauru, SP, Brazil \\ ${ }^{\mathrm{b}}$ Health Sciences Center, University of the Sacred Heart (USC), Bauru, SP, Brazil \\ ${ }^{\mathrm{c}}$ Human Morphophysiology (Anatomy), University of Marilia (UNIMAR), Marilia, SP, Brazil \\ d Center for the Study of Venoms and Venomous Animals (CEVAP), São Paulo State University (Univ. Estadual Paulista, UNESP), Botucatu, SP, Brazil
}

\section{A R T I C L E I N F O}

\section{Keywords:}

Fibrin tissue adhesive

Facial nerve

Nerve regeneration

Low-level laser therapy

\begin{abstract}
A B S T R A C T
This research evaluated the influence of Photobiomodulation Therapy (PBMT) on lesions of the facial nerve repaired with the end-to-side technique or coaptation with a new heterologous fibrin sealant. Thirty-two Wistar rats were separated into 5 groups: Control group (CG), where the buccal branch of the facial nerve was collected; Experimental Suture Group (ESG) and Experimental Fibrin Group (EFG), in which the buccal branch was end-toside sutured to the zygomatic branch on the right side of the face or coaptated with fibrin sealant on the left side; Experimental Suture Laser Group (ESLG) and Experimental Fibrin Laser Group (EFLG), in which the same procedures were performed as the ESG and EFG, associated with PBMT (wavelength of 830 nm, energy density $6.2 \mathrm{~J} / \mathrm{cm}^{2}$, power output $30 \mathrm{~mW}$, beam area of $0.116 \mathrm{~cm}^{2}$, power density $0.26 \mathrm{~W} / \mathrm{cm}^{2}$, total energy per session $2.16 \mathrm{~J}$, cumulative dose of $34.56 \mathrm{~J}$ ). The laser was applied for $24 \mathrm{~s} /$ site at 3 points on the skin's surface, for a total application time of $72 \mathrm{~s}$, performed immediately after surgery and 3 times a week for 5 weeks. A statistically significant difference was observed in the fiber nerve area between the EFG and EFLG (57.49 \pm 3.13 and $62.52 \pm 3.56 \mu \mathrm{m}^{2}$, respectively). For the area of the axon, fiber diameter, axon diameter, myelin sheath area and myelin sheath thickness no statistically significant differences were found $(p<0.05)$. The functional recovery of whisker movement occurred faster in the ESLG and EFLG, which were associated with PBMT, with results closer to the CG. Therefore, PBMT accelerated morphological and functional nerve repair in both techniques.
\end{abstract}

\section{Introduction}

Nerve injuries may occur due to several types of trauma, such as lacerations with sharp objects, gunshot wounds, crushing, fractures, tumor resections, orthognathic surgeries, and motor vehicle accidents [1-5]. Damage to the facial nerve (FN) can lead to functional alterations such as asymmetry and loss of facial expression, causing disorders related to self-image and recognition of the individual, as well as mental health alterations, suffering, and social isolation [4,6-9].

When the distal and proximal stumps of the damaged nerve are isolated and distant, it is difficult to apply the end-to-end neurorrhaphy technique, which is considered the gold standard $[9,10]$, so an alternative technique may be used, the end-to-side neurorrhaphy [11]. This repair technique is based on the use of a graft with donor nerves that, laterally connected to the nerve to be recovered, provides axonal sprouting of the intact nerve to the receiver nerve. This technique may be applied to different nerves, including the facial nerve $[3,12-16]$.

Aiming to establish an environment that is less invasive than traditional repair suturing (the gold standard), new surgical adhesives has been created, such as collagen, fibrin glue, cyanoacrylate, and gelatin.

\footnotetext{
* Corresponding author at: Department of Biological Sciences (Anatomy), Bauru School of Dentistry, University of São Paulo (USP), Alameda Dr. Octávio Pineiro Brisola 9-75, Vila Nova Cidade Universitária, CEP 17012-901 Bauru, São Paulo, Brazil.

E-mail address: marcelierosso@fob.usp.br (M.P.d.O. Rosso).
} 
The new heterologous fibrin sealant (NHFS) is extracted from snake venom (Crotalus durissus terrificus) and, because it does not contain human blood, it avoids the possible transmission of infectious diseases. It is a clinically useful tool due to its flexibility and variety of applications, demonstrating a good bond strength and biocompatibility, having an important role in cell and tissue regeneration process [17-26].

Therapy using physical methods such as therapeutic ultrasound and photobiomudalation therapy (PBMT) may provide the benefits of faster functional and nerve recovery [27-32]. PBMT demonstrates therapeutic effects such as local analgesia, antiedema action, anti-inflammatory and healing actions, and tissue biostimulatory effects that may provide an increase in the speed of growth of sectioned nerves $[27,33]$.

The photostimulatory effect of PBMT refers to its absorption by the tissues through photoreceptors, facilitating mitochondrial respiration, creation of adenosine triphosphate (ATP), additional transportation of $\mathrm{Ca}^{2+}$ in the cytoplasm, and the beginning of conducted pathways mediated by reactive oxygen species (ROS), cyclic adenosine monophosphate (AMP) and nitric oxide. These effects lead to stimulation of various transcription factors related to migration and cell proliferation, promoting tissue repair and regeneration $[27,34,35]$. The transcription factors NF-kB and HIF-1 $\alpha$ NRF2 can be activated, causing a decrease in the inflammatory response, playing an important role in the repair process [36-40].

The performance of low-level lasers associated with the use of the NHFS in end-to-side repair of damaged facial nerves is still not established, especially in anatomical and functional aspects. In view of this, the objective of the current study was to evaluate the influence of PBMT on damaged terminal branches of the FN repaired through the end-toside technique with epineural suture or coaptation with the NHFS.

\section{Materials and Methods}

\subsection{Animals}

The experimental research procedures were approved by the Ethics Committee on Research in Animals of the Bauru School of Dentistry, University of São Paulo (São Paulo, Brazil), with the Protocol number 007/2013.

Thirty-two male Wistar rats (Rattus norvegicus) were used. They were 80 days old and the average weight was $250 \mathrm{~g}$. The animals remained in appropriate boxes with no movement restrictions and received water and food ad libitum. They were exposed to an approximate temperature of $22^{\circ} \mathrm{C}$, with a 12-hour regime of light and dark, obtained by use of a timer in the animal maintenance room.

\subsection{Experimental Groups}

The animals were randomly divided into 1 control group (CG) and 4 experimental groups (EG), as described below:

1. Control group (CG): Consisting of 8 animals that were not submitted to surgical procedures or PBMT, where the buccal branch of the facial nerve (BBFN) was dissected and collected for histomorphological and histomorphometric analysis.

2. Experimental suture group (ESG) and experimental fibrin group (EFG): Consisting of 12 animals in which the BBFN was sectioned on both sides of the face, but on the right side, an end-to-side graft suture was used to connect the distal stump of the buccal branch (dsBB) to the zygomatic branch of the facial nerve (ZBFN), whereas on the left side, the same procedures were performed, using the NHFS for coaptation.

3. Experimental suture laser group (ESLG) and experimental fibrin laser group (EFLG) associated with PBMT: Consisting of 12 animals that underwent the same surgical procedures as those in the ESG and EFG, in combination with PBMT.

\subsection{New Heterologous Fibrin Sealant}

Venom from Crotalus durissus terrificus snakes was milked at State University of São Paulo (UNESP), more specifically Center for the Study of Venoms and Venomous Animals (CEVAP) and pooled according to good manufacturing practices (GMP). All the snakes are microchipped to ensure the traceability of the venom lots used in the composition of heterologous fibrin sealant. After filtration and lyophilization, the venoms are stored in the Venoms Bank of CEVAP. Cryoprecipitate is the insoluble fraction, a cold precipitate of frozen fresh plasma (FFP) from Bubalus bubalis buffalos. It contains fibrinogen, factor VIII (F VIII), Willebrand factor (F vW), factor XIII (F XIII) and fibronectin.

It must contain at least 80 units of factor VIII and between 150 and $250 \mathrm{mg}$ of fibrinogen. Each unit has a volume from 10 to $20 \mathrm{ml}$, which must be stored at $-20^{\circ} \mathrm{C}$ and has a shelf life of one year. In sum, the cryoprecipitate extracted to be applied as a new heterologous fibrin sealant standardized by CEVAP is a product that is safe and free from undesirable substances. The formulation, as well as its storage, handling and dosage are described in detail in the internationally required patents (PCT/BR2015/000065 and PCT/BR2015/000064) [17,18,21,22].

At the time in experimental surgery, the components were first thawed, then reconstituted, mixed, and applied according to the following protocol: The first bottle (Eppendorf ${ }^{\circledast}$ ) contained fibrinogen obtained from buffalo blood $(5 \mu \mathrm{l})$; the second contained calcium chloride ( $2 \mu \mathrm{l})$; and the last bottle contained a thrombin-like fraction $(1 \mu \mathrm{l})$; for a total of $8 \mu \mathrm{l}$. The production process was described in Ferreira Junior et al. [41].

\subsection{Surgical Procedures}

To perform the surgical procedures, at 80 days old, all of the animals in the experimental groups (ESG, EFG, ESLG and EFLG) were weighed and underwent general anesthesia through an intramuscular injection of the anesthetic Zoletil $50^{\circledR}$ (Virbac of Brazil), which contains a 1:1 ratio $(125: 125 \mathrm{mg})$ of tiletamine hydrochloride and zolazepam hydrochloride $(0.15 \mathrm{ml} / \mathrm{kg} / \mathrm{IM})$. Then, the animals were submitted to asepsis, trichotomy and positioning of the animal in the lateral decubitus position.

Initially an incision was made on the face with a No. 15 scalpel blade (approximately from the tragus of the ear toward the labial commissure), with subsequent incision to expose the BBFN, which was sectioned with straight-tip scissors (Fig. 1A) without removing fragments observed on the surgical microscope (DFV, Brazil). The proximal stump of the BBFN was positioned end-to-side to the ZBFN.

In the ESG, an end-to-side epineural suture with 10-0 nylon monofilament (Ethicon ${ }^{\circledR}$, Johnson \& Johnson, Brazil) was performed on the right side of the face. In the EFG, the nerve stumps were approximated and coaptation with the NHFS (Fig. 1B) on the left side of the face. The surgery was finished with skin sutures using 4-0 silk thread (Ethicon ${ }^{\circledR}$, Johnson \& Johnson, Brazil).

The same surgical procedures were performed on the ESLG and EFLG animals, adding PBMT.

\subsection{Photobiomodulation Therapy}

In groups ESLG and EFLG, photobiomodulation therapy (PBMT) was applied to the surgical sites on the animals with a continuous pulse using a gallium-aluminum-arsenide laser (GaAlAs, Laserpulse IBRAMED $^{\circledR}$, Brazil). The protocol used was: wavelength of $830 \mathrm{~nm}$, energy density of $6.2 \mathrm{~J} / \mathrm{cm}^{2}$, with optical power output potency of $30 \mathrm{~mW}$, power density of $0.26 \mathrm{~W} / \mathrm{cm}^{2}$, beam area of $0.116 \mathrm{~cm}^{2}$, total energy per session of $2.16 \mathrm{~J}$ and cumulative dose of $34.56 \mathrm{~J}$. Each laser application session was applied for $24 \mathrm{~s} /$ site at 3 points in the perpendicular surgical area on the skin's surface, for a total application 

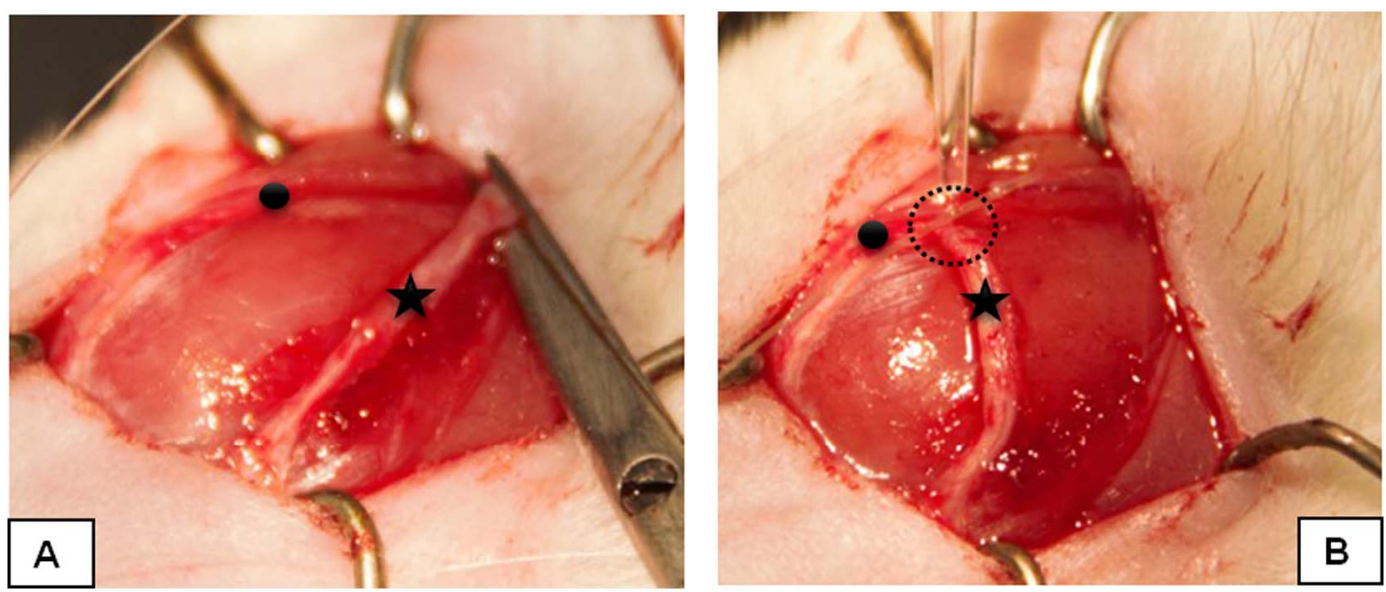

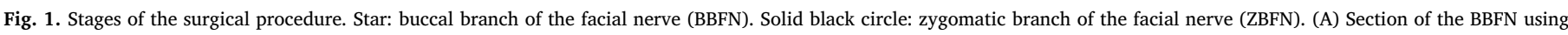

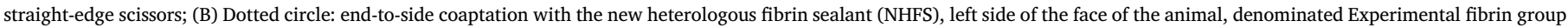
(EFG) and Experimental fibrin laser group (EFLG).

time of $72 \mathrm{~s}$. This was conducted immediately following surgery and 3 times a week for a total of 5 weeks. Laser beam emissions were calibrated by the device itself during application.

\subsection{Functional Analysis}

At 10 weeks post-surgery, the animals were submitted to observation of whisker movements, both spontaneous and provoked by the researcher, by palms beaten 3 or 4 times in order to trigger larger movements. The animals were evaluated in the black box to provide greater contrast with the white wires of the whisker and the observation was always made by the same researcher that was blinded by which group the animal belonged to evaluate the movements of the whiskers.

The score of the movements, according to Table 1, was performed at the moment of the movement stimulus and confirmed by photographs. The average values were recorded at the fifth and tenth week after surgery. The researcher classified the movements of the whiskers according to the scale below [42].

\subsection{Optical Microscopy (OM) and Transmission Electron Microscopy (TEM) Analysis}

At 10 weeks post-surgery $[43,44]$, the animals in the control group and the experimental groups were euthanized with an overdose of anesthesia in order to collect samples. The following samples were collected: the intact BBFN from the control group; and the distal stump of the buccal branch of the facial nerve immediately after the suture site (ESG and ESLG) or coaptation with fibrin sealant (EFG and EFLG), grafting approximately $1 \mathrm{~cm}$.

Nerve samples were set in Karnovsky's fixative for $24 \mathrm{~h}$; and then $\mathrm{OM}$ and TEM were carried out in a laboratory, including the use of the mounting media, HistoResin (Leica Mycrosistems ${ }^{\circledast}$, Germany). Ultrathin cross-sections $(5 \mu \mathrm{m})$ of the fascicles were obtained and

Table 1

Table used to analyze the movement of whiskers, elaborated by de Faria et al. [42].

\begin{tabular}{lll}
\hline \multicolumn{2}{l}{ Scale observation whiskers } & \\
\hline Score & Movement & Position \\
\hline 1 & Without movement & Posterior \\
2 & Slight tremor & Posterior \\
3 & Increased tremor & Posterior \\
4 & Normal movement & Posterior \\
5 & Normal movement & Anterior \\
\hline
\end{tabular}

stained with $1 \%$ toluidine blue for optical microscopy.

\subsection{Morphometric and Functional Statistical Analysis}

For the morphometric analysis, the following measurements were made: the area and diameter of the fibers; the area and diameter of the axon; and the area and thickness of the myelin sheath.

The images were captured using an Olympus ${ }^{\circledR}$ microscope (Japan), and photographs were taken with a coupled digital camera (Olympus $^{\circledR}$ DP 71, Japan), so the measurements could be obtained. A quantitative analysis was possible with Image Pro-Plus 6.0 (Media Cybernetics ${ }^{\circledR}$, USA). Statistical analysis was performed using ANOVA, followed by the Tukey's test. The level of significance for the comparisons was set at $p<0.05$. To analyze the functional evaluation data for whisker movement, Fisher's exact test was used, as in Farrag et al. [45].

The scores obtained from the evaluation of the movement and the final position of the whiskers were analyzed in the 5th and 10th weeks by the unpaired $t$-test ( $\alpha$ significance level $<0.05$ ), obtaining the mean and standard deviation. The analysis was performed with GraphPad software (La Jolla, CA, USA).

\section{Results}

\subsection{Optical Microscopy}

Nerve fibers with myelin sheaths presented regular shapes and sizes in the animals of the control group. Myelinated and unmyelinated fibers in the dsBB were present in all animals of all experimental groups. These nerve fibers presented irregular morphology and heterogeneous sizes. Moreover, the presence of blood vessels in the nerve fascicles was shown in the photomicrography (Fig. 2).

\subsection{Transmission Electron Microscopy}

In the control group the TEM showed intact nerves with uniformity of myelinated fibers in relation to their size and form, as well as the presence of nucleus of Schwann cells. In turn, the analysis of the ESG and EFG showed that the myelinated fibers were present and placed in an orderly manner, but exhibited irregularities in shape in comparison with the unmyelinated fibers, as well as the presence of nucleus of Schwann cells. In the groups that received treatment with the PBMT (the ESLG and the EFLG), the myelinated fibers were found to be similar to those of the ESG and EFG. Also, the presence of collagen fibers around the regenerated nerve fibers was shown in the distal stump (Fig. 3). 


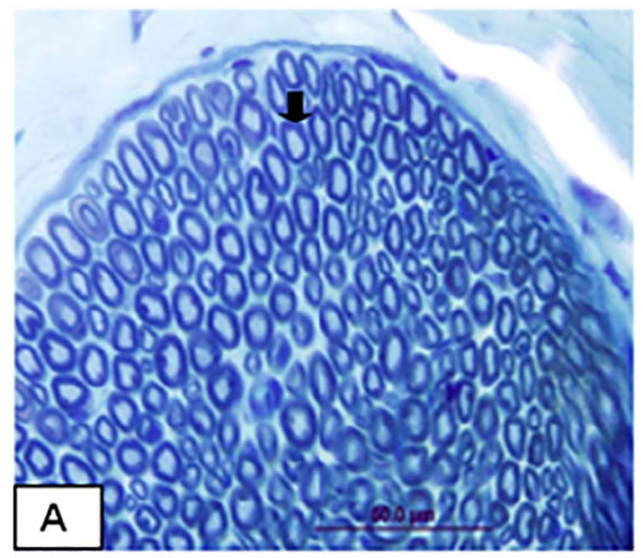

Fig. 2. Microscopic aspect of the studied groups. $100 \times$ objective and indicative increase in image by scale bars. Black rhombus: blood vessel. Black arrow: myelinated fiber. (A) Intact nerve in the Control Group (CG); (B) Experimental suture group (ESG) and (C) Experimental fibrin group (EFG) showed irregularly arranged myelinated fibers and blood vessels; (D) Experimental suture laser group (ESLG) and (E) Experimental fibrin laser group (EFLG) exhibited myelinated fibers with irregular arrangement.
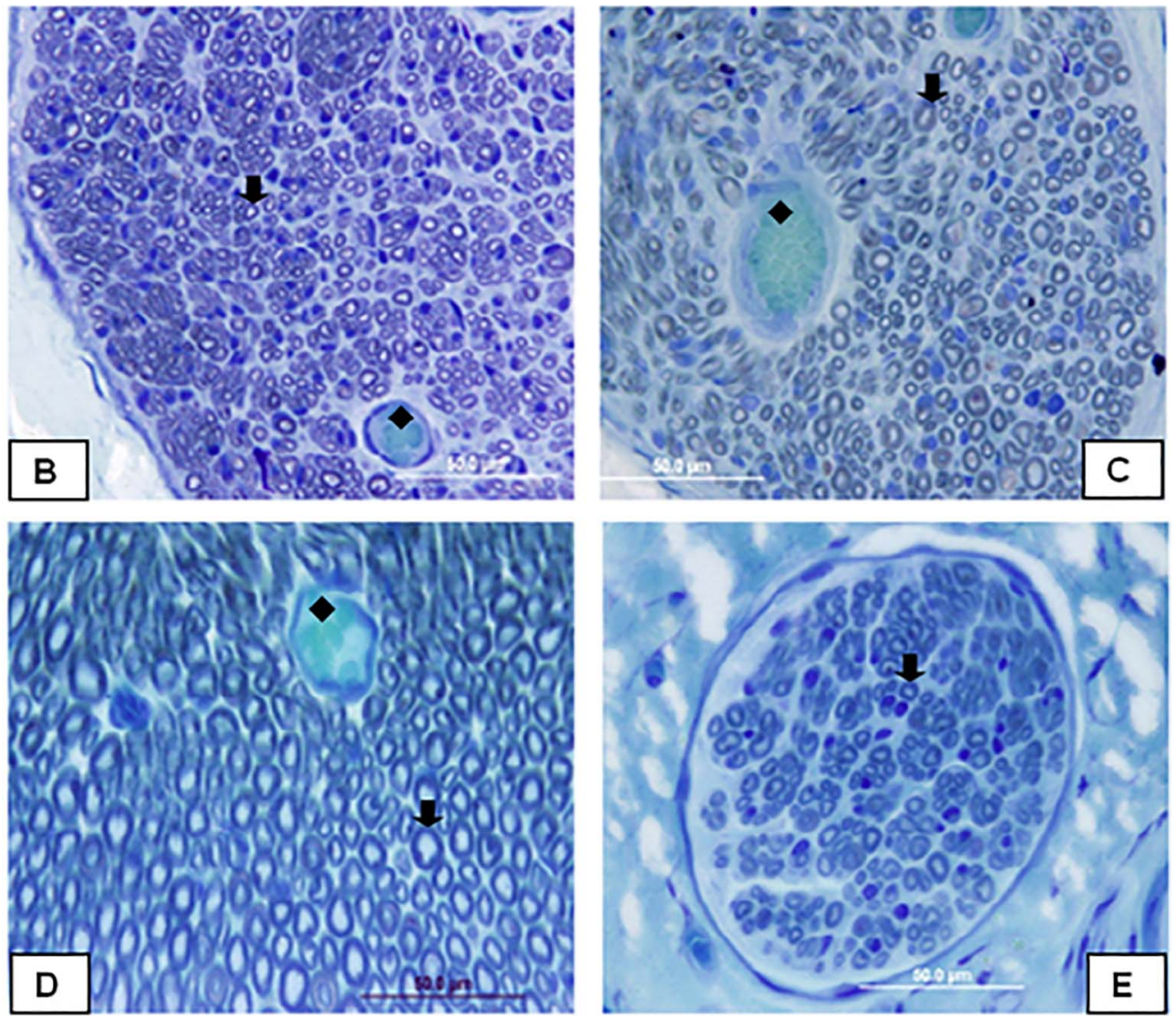

\subsection{Histomorphometric Analysis}

Table 2 presents the morphometric results, which showed a statistically significant difference for comparison of the area of the nerve fiber between the EFG $(57.49 \pm 3.13 ; p<0.05)$ and the group that received PBMT (EFLG: $62.52 \pm 3.56 ; p<0.05$ ). For the area of the axon, fiber diameter, axon diameter, myelin sheath area and myelin sheath thickness no statistically significant differences were found $(p<0.05)$ (Fig. 4).

\subsection{Functional Analysis}

The control group was used as a reference standard for normality of whisker position and movement (score of 5), according to the parameters established in Table 1 and developed by de Faria et al. (Fig. 5A and $\mathrm{B})$.

In the fifth week after surgery, the verified mean score of the ESG was 4 (Fig. 5C, right side of the face) and that of the EFG was 4.2 (Fig. 5C, left side of the face). In relation to the groups treated with PBMT, the mean score of the ESLG was 4.4 (Fig. 5E, right side), and the EFLG scored a value of 4.6 (Fig. 5E, left side). A score of 4 represents normal whisker movement and posterior positioning.

In the tenth week after surgery, the mean score of the ESG was 4.4 (Fig. 5D, right side) and that of the EFG was 4.6 (Fig. 5D, left side). For the groups that received PBMT, the mean value for the ESLG was 4.7 (Fig. 5F, right side), and that for the EFLG was 4.8 (Fig. 5F, left side), with normal whisker movement and anterior whisker positioning similar to the CG.

The mean and standard deviation values of scores after functional analysis of the whiskers at 5 and 10 weeks after surgery are shown in Fig. 6. 

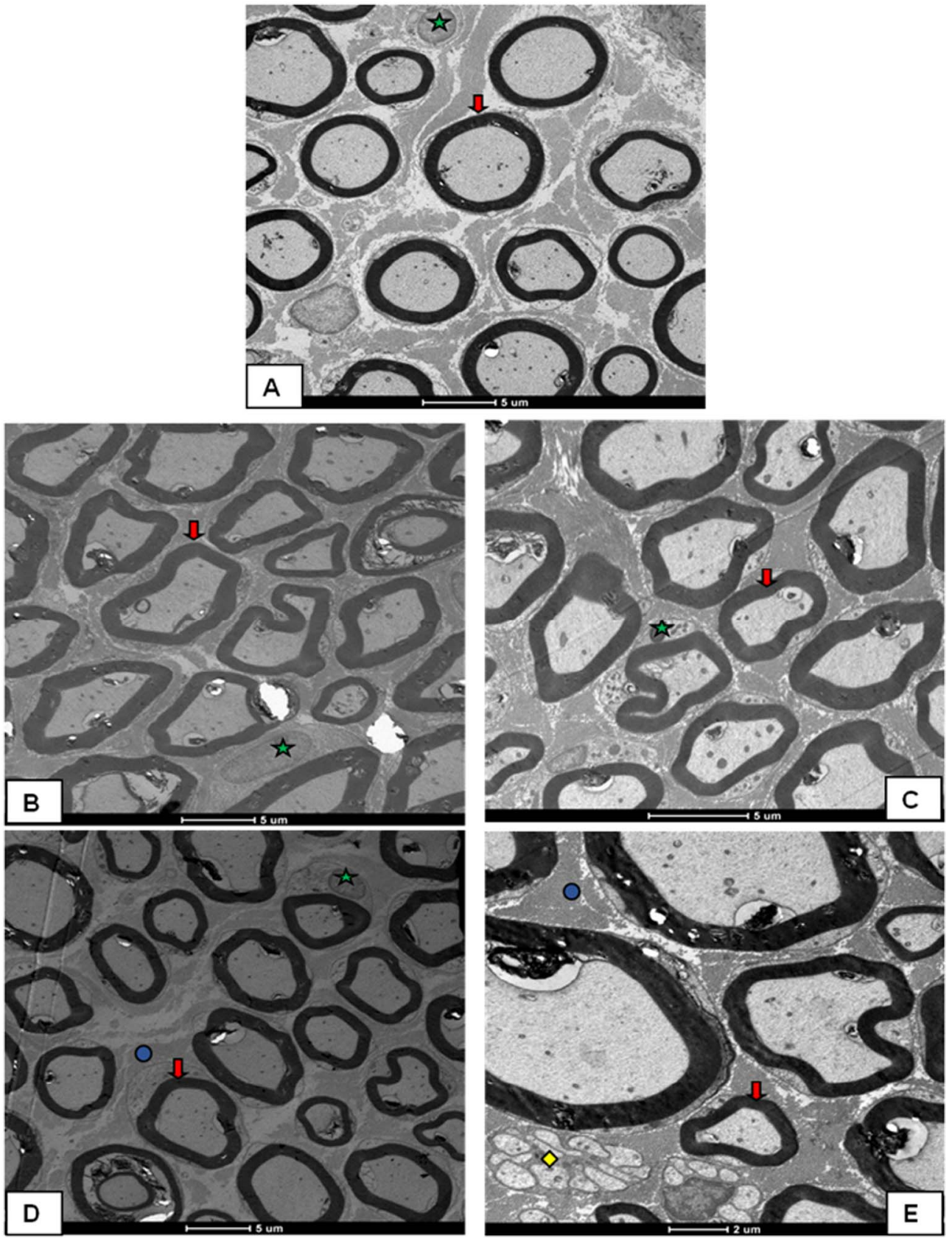

Fig. 3. Ultrastructural aspects of Transmission electron microscopy (TEM) of the studied groups in the distal stump of the buccal branch (dsBB) after a 10-week postoperative period. Red arrow: myelinated fiber. Yellow rhombus: unmyelinated fiber. Blue circle: collagen fiber. Green star: nucleus of Schwann cell. (A) CG with intact buccal branch of the facial nerve; (B) ESG and (C) EFG with irregular arrangement of myelinated fibers and evidence of nucleus of Schwann cells; (D) ESLG and (E) EFLG with presence of collagen fibers, myelinated and unmyelinated fibers. (For interpretation of the references to colour in this figure legend, the reader is referred to the web version of this article.)

\section{Discussion}

The present study aimed at comparing, through morphologic and functional analysis, the regeneration of the BBFN through two ways of using the end-to-side technique: using the NHFS or the epineural suture, associated with PBMT or not. The results showed that the use of the NHFS is an effective, easy-to-use method for repairing damaged peripheral nerves, and that PBMT accelerated this process.

Microscopic analysis showed the presence of myelinated and unmyelinated fibers regenerated with irregular shape and heterogeneous sizes inside the dsBB, as well as blood vessels, in all experimental groups. These characteristics are similar to those shown in a process of nerve regeneration in previous studies $[3,26,46,47]$. The use of sutures and sealant allowed the migration of axons to the distal stump. The

Table 2

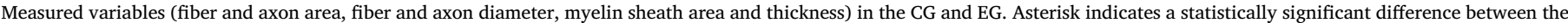
groups with ANOVA, by the Tukey's test ( $p<0.05$ ), and observed in the variable fiber area between the EFG and EFLG (column).

\begin{tabular}{|c|c|c|c|c|c|c|}
\hline Groups & Fiber area $\left(\mu \mathrm{m}^{2}\right)$ & Axon area $\left(\mu \mathrm{m}^{2}\right)$ & Fiber diameter $(\mu \mathrm{m})$ & Axon diameter $(\mu \mathrm{m})$ & Myelin sheath area $\left(\mu \mathrm{m}^{2}\right)$ & Myelin sheath thickness $(\mu \mathrm{m})$ \\
\hline CG & $60.42 \pm 3.84$ & $20.74 \pm 2.06$ & $11.66 \pm 1.65$ & $7.22 \pm 1.23$ & $39.69 \pm 5.12$ & $2.22 \pm 1.27$ \\
\hline ESG & $57.84 \pm 5.59$ & $18.71 \pm 1.57$ & $9.87 \pm 1.66$ & $6.46 \pm 1.12$ & $39.12 \pm 5.50$ & $1.70 \pm 1.05$ \\
\hline EFG & $57.49 \pm 3.13^{*}$ & $18.92 \pm 2.29$ & $9.88 \pm 1.11$ & $6.69 \pm 0.93$ & $38.57 \pm 2.80$ & $1,59 \pm 0.82$ \\
\hline ESLG & $60.67 \pm 3.79$ & $19.71 \pm 1.65$ & $11.01 \pm 1.51$ & $6.96 \pm 1.04$ & $40.96 \pm 4.76$ & $2.02 \pm 1.14$ \\
\hline EFLG & $62.52 \pm 3.56^{*}$ & $20.55 \pm 1.55$ & $11.39 \pm 1.81$ & $7.25 \pm 1.10$ & $41.97 \pm 4.48$ & $2.07 \pm 0.95$ \\
\hline
\end{tabular}


Fiber Area

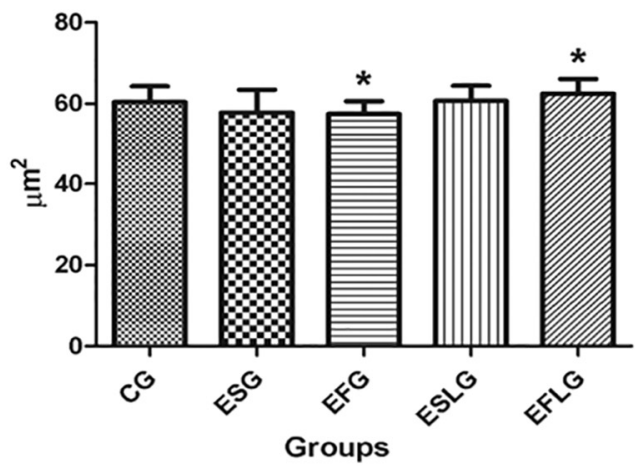

Fiber Diameter

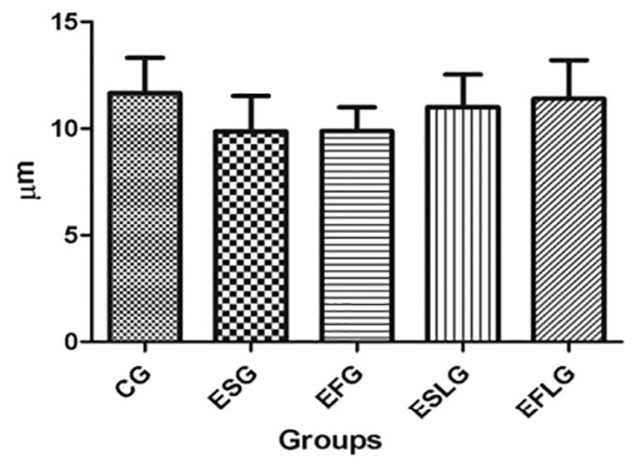

Myelin Sheath Area

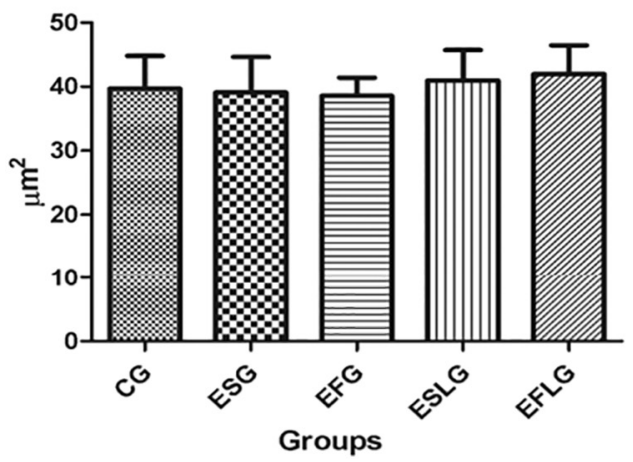

Axon Area

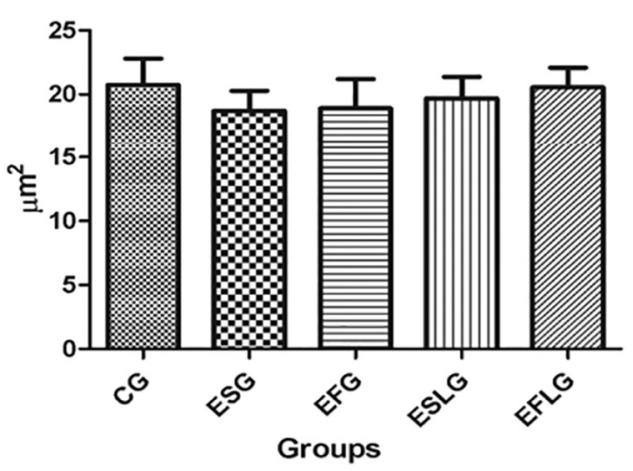

Axon Diameter

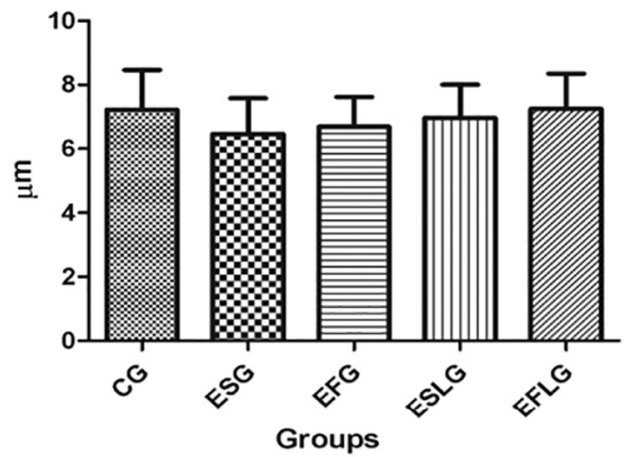

Myelin Sheath Thickness

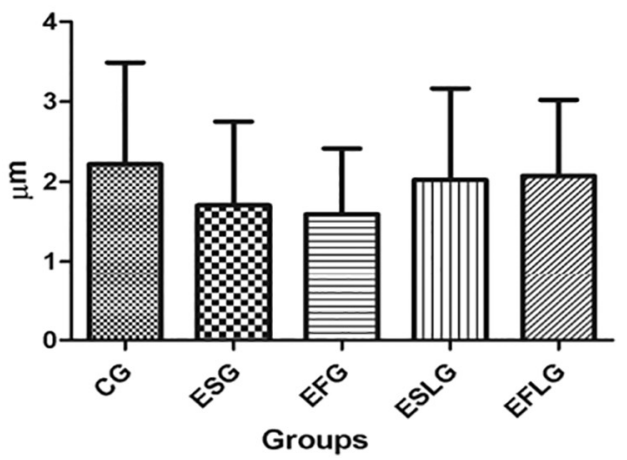

Fig. 4. Graphical view of the variables measured by analysis of the distal stump of the buccal branch (dsBB) after a 10-week postoperative period. A statistically significant difference $(p<0.05)$ was observed in the area of the nerve fiber in the groups that used the fibrin sealant (EFG and EFLG). In relation to the other measured variables, no significant differences were observed. fibrin sealant reduced surgical time and was easier to apply, while maintaining functionality and providing an effective technique for peripheral nerve repair $[18,23,26]$. The sealant provided a reduction of $70 \%$ in surgical time in comparison to the epineural suture [48], and has the advantage of being adhesive and flexible [18].

Analysis by TEM showed that the myelinated fibers were arranged in an orderly manner, but demonstrated a more regular shape in the control group than in the experimental groups, as well as the presence of unmyelinated fibers, nucleus of Schwann cells, and collagen fibers. These findings are consistent with a study on nerve regeneration that found the presence of myelinated and unmyelinated fibers close to the nucleus and random guidance of tissue under regeneration [26]. The presence of collagen fibers between regenerated nerve fibers offers biological support for growth and differentiation of cells $[49,50]$. PBMT studies indicated its ability to assist in the synthesis of collagen; in addition, the collagen arrangement demonstrates better organized [26,29,51-55].

Histomorphometry showed higher mean values for all the variables in the groups using PBMT (ESLG and EFLG), and values that were closer to the CG, with a statistically significant difference between the EFG and EFLG in the area of the nerve fiber. The best results on the morphometric measurements of regenerated nerves are associated to the beneficial effects of PBMT, which, through the penetration of laser light into tissues, may stimulate increased mitochondrial ATP production, blood supply and collagen synthesis, as well as increased proliferation of Schwann cells. PBMT also has analgesic, anti-inflammatory and antiedema effects [56-63]. These photostimulatory effects depend on a series of parameters, such as energy, time, wavelength, density of energy, irradiance, peak power, pulse width per rest period, and pulse frequency [64].

The ESLG and EFLG presented better functional recovery for both periods (5 and 10 weeks), as shown by analysis of whisker movement, especially in the EFLG, which used NHFS associated with PBMT. A study by Farrag et al. [45] showed better recovery of whisker movement with the use of sutures in comparison to homologous fibrin sealant. In lesions of the terminal branches of the FN, the assessment of movement is one the methods used to confirm regeneration and proper restoration of damaged neural circuits, confirming appropriate integration with facial motor commands [42,65-67].

PBMT has been related to the acceleration of the healing process 

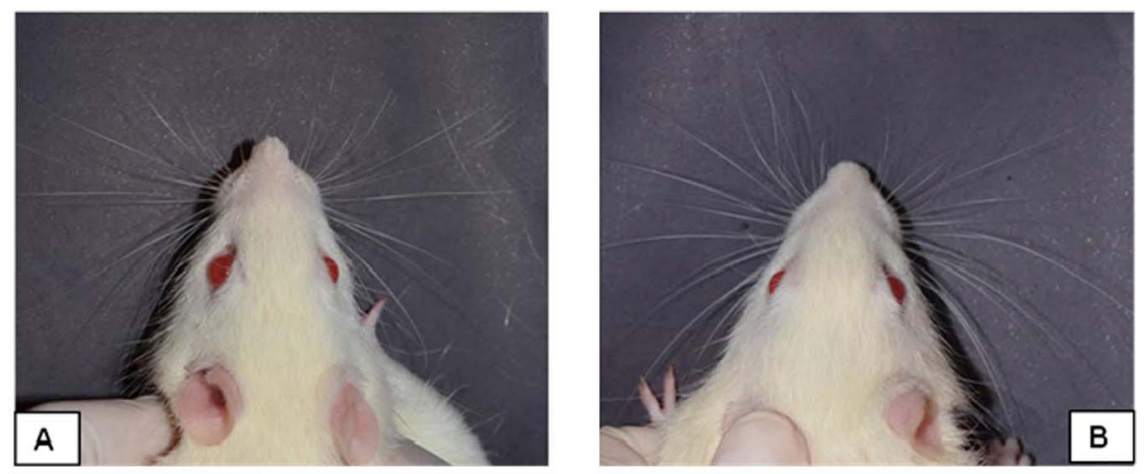

Fig. 5. Demonstration of whisker position: (A) Fifth week and (B) tenth week of the CG (normal position); (C) fifth week and (D) tenth week of the ESG (right side) and EFG (left side); (E) fifth week and (F) tenth week of the groups that received photobiomodulation: ESLG (right side) and EFLG (left side). On the scale used, a score of 4 refers to normal movement with posterior positioning of the whiskers, and a score of 5 is normal movement of the whiskers with anterior positioning.
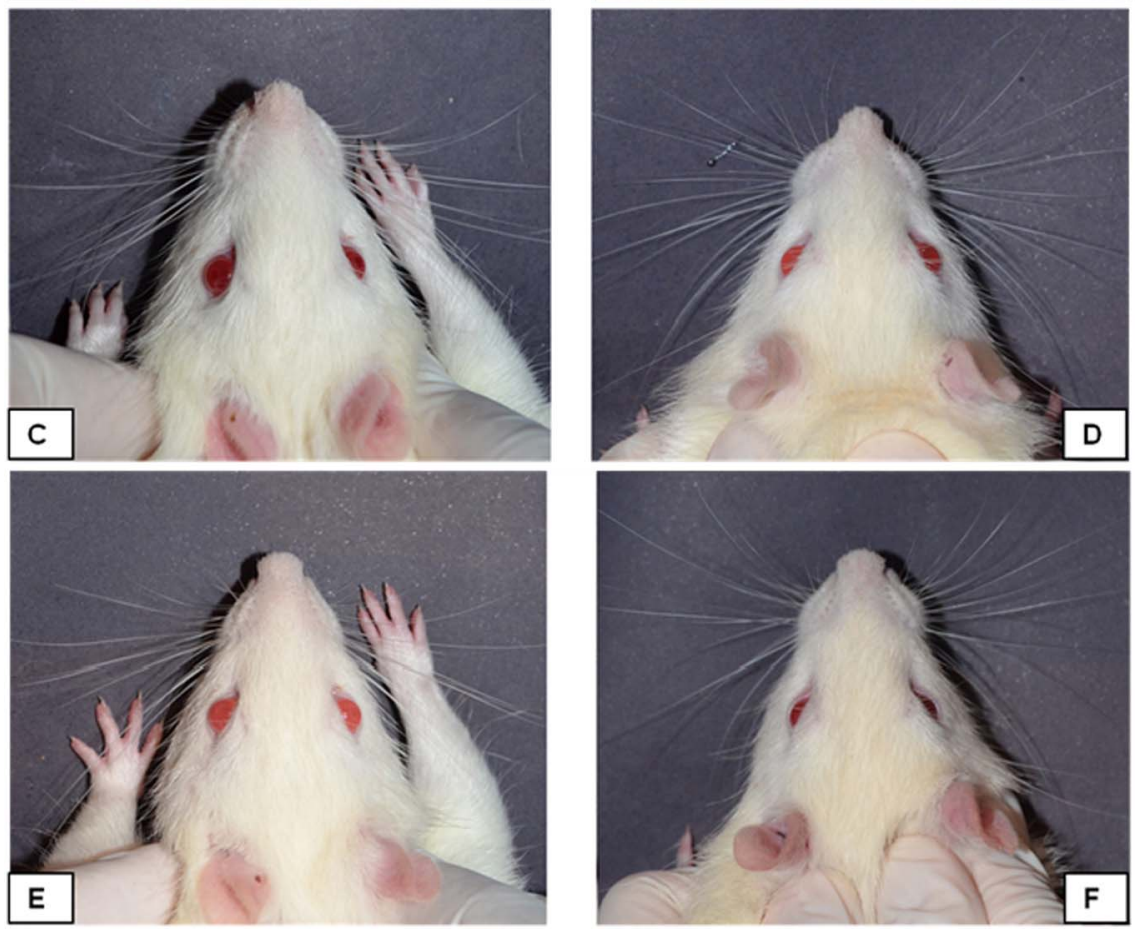

[68-70], when its application is made early after injury to the peripheral nerve [26]. PBMT is an important tool in health areas such as Physiotherapy, Dentistry and Medicine in the post-traumatic rehabilitation process [71]. Gio-Benato et al. [72] showed that treatment with PBMT $830 \mathrm{~nm}$ provided a faster rate of recovery of function and regeneration of nerve fibers. Similar results were found by Khullar et al. [73] with the use of PBMT $820 \mathrm{~nm}$ and by Miloro et al. [74] with PBMT at $820-830 \mathrm{~nm}$, adding the observation of increased nerve fiber density.
The laser application protocol used in the present study research was based on previous studies that have demonstrated positive effects of PBMT on the regenerative process and acceleration of the recovery of lesions, as well as good tissue penetration capacity [23,26,75]. The parameters used (for example, wavelength of $830 \mathrm{~nm}$, power density of $258.6 \mathrm{~mW} / \mathrm{cm}^{2}$ and energy density of $6.2 \mathrm{~J} / \mathrm{cm}^{2}$ ) led to improved nerve repair, showing higher mean values in all the variables in the experimental groups (ESLG and EFLG) associated with PBMT [26].
5 weeks

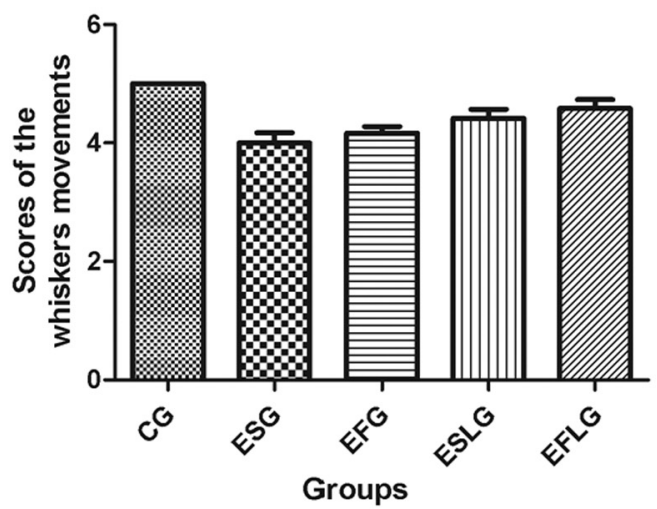

10 weeks

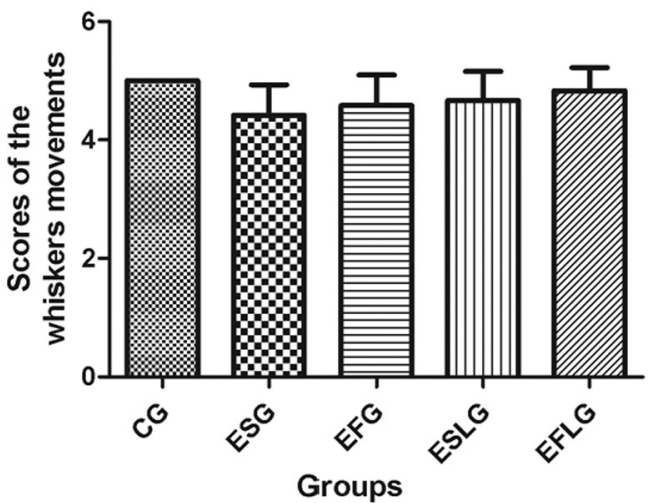

Fig. 6. Graphical view of the mean and the standard deviation of functional analysis (movement and position of the whiskers). Functional results 5 and 10 weeks after surgery. 
In one study, PBMT (GaAlAs $808 \mathrm{~nm}$, continuous) provided functional gait recovery and increased myelin sheath thickness, in addition to neuronal growth as scored by the GAP43 marker [76]. In another study, this type of PBMT (GaAlAs $808 \mathrm{~nm}$ and power of $300 \mathrm{~mW}$ ) was related to reduction of inflammatory cytokines and facilitated neural regeneration, as demonstrated by molecular analyzes of levels of TNF-a, IL-1b and GAP-43, in addition to attenuating pain-related behaviors [53]. However, parameters such as wavelength, type of wave (pulsed or continuous), energy density, and time of exposure to the laser remain controversial in the literature [29,71-73].

The implementation of electromyographic studies complements physiological evaluations of the nerve regeneration process; this could be considered a limitation of the present study [77]. Future research could include comparative analysis between PBMT with new photodynamic therapies, such as near-infrared light-emitting diodes [78], verification of neurotrophic factors, and standardization of the protocols for laser application.

\section{Conclusion}

The use of low-level laser therapy in damaged terminal branches of the facial nerve that were repaired end-to-side by two techniques (suture or fibrin sealant) presented better morphofunctional results. In addition, the use of a new heterologous fibrin sealant enabled the manipulation of the stumps with a minimization of trauma, and is therefore a good alternative for peripheral nerve repair.

\section{Conflict of Interest}

There was no conflict of interest.

\section{References}

[1] U. Ozsoy, A. Hizay, B.M. Demirel, O. Ozsoy, S. Bilmen Sarikcioglu, M. Turhan, et al., The hypoglossal-facial nerve repair as a method to improve recovery of motor function after facial nerve injury, Ann. Anat. 193 (2011) 304-313.

[2] G. Hundeshagen, K. Szameit, H. Thieme, M. Finkensieper, D.N. Angelov, O. Guntinas-Lichius, et al., Deficient functional recovery after facial nerve crush in rats is associated with restricted rearrangements of synaptic terminals in the facial nucleus, Neuroscience 248 (2013) 307-318.

[3] K. Matsuda, M. Kakibuchi, Y. Sotsuka, T. Kubo, M. Shibata, K. Hosokawa, End-toside "loop" graft for total facial nerve reconstruction: over 10 years experience, J. Plast. Reconstr. Aesthet. Surg. 68 (2015) 1054-1063.

[4] D.C. Bowe, E.A. Gruber, N.M. McLeod, Nerve injury associated with orthognathic surgery. Part 1: UK practice and motor nerve injuries, Br. J. Oral Maxillofac. Surg. 54 (2016) 362-365.

[5] G.Z. Zhang, T. Su, J.M. Xu, Z.Q. Cheng, Clinical retrospective analysis of 9 cases of intraparotid facial nerve schwannoma, J. Oral Maxillofac. Surg. 74 (2016) $1695-1705$.

[6] D. Lad, N. Sharma, R.D. Wurster, S.J. Marzo, K.J. Jones, E.M. Foecking, Electrical stimulation facilitates rat facial nerve recovery from a crush injury, Otolaryngol. Head Neck Surg. 139 (2008) 68-73.

[7] T. Hadlock, R. Lindsay, C. Edwards, C. Smitson, J. Weingberg, C. Knox, et al., The effect of electrical and mechanical stimulation on the regenerating rodent facial nerve, Laryngoscope 120 (2010) 1094-1102.

[8] R. Post, K.S. de Boer, M.J. Malessy, Outcome following nerve repair of high isolated clean sharp injuries of the ulnar nerve, PLoS One 7 (2012) e47928.

[9] R. Salomone, R.F. Bento, H.J. Costa, D. Azzi-Nogueira, P.C. Ovando, C.F. Da-Silva, et al., Bone marrow stem cells in facial nerve regeneration from isolated stumps, Muscle Nerve 48 (2013) 423-429.

[10] J.T. Heaton, S.H. Sheu, M.H. Hohman, C.J. Knox, J.S. Weinberg, I.J. Kleiss, et al., Rat whisker movement after facial nerve lesion: evidence for autonomic contraction of skeletal muscle, Neuroscience 265 (2014) 9-20.

[11] F. Viterbo, J.C. Trindade, K. Hoshino, A. Mazzoni Neto, Latero-terminal neurorrhaphy without removal of the epineural sheath. Experimental study in rats, Rev. Paul. Med. 110 (1992) 267-275 (Erratum in: Rev Paul Med. 111 (1993) 479).

[12] D.N. Silva, J. Coelho, F.O. Frazílio, A.N. Odashiro, P.T. Carvalho, E.R. Pontes, et al., End-to-side nerve repair using fibrin glue in rats, Acta Cir. Bras. 25 (2010) 158-162.

[13] S.F. Mueller, F.V. Oliveira Neto, L.F. Franciosi, Experimental model of use the endto-side neurorrhaphy in rats brachial plexus, Rev. Bras. Cir. Plást. 24 (2009) 420-424.

[14] P. Haninec, L. Mencl, R. Kaiser, End-to-side neurorrhaphy in brachial plexus reconstruction, J. Neurosurg. 119 (2013) 689-694.

[15] H.F. Liu, Z.G. Chen, T.L. Fang, P. Arnold, W.C. Lineaweaver, J. Zhang, Changes of the donor nerve in end-to-side neurorrhaphies with epineurial window and partial neurectomy: a long-term evaluation in the rat model, Microsurgery 34 (2014) $136-144$.

[16] J.E. Shea, J.W. Garlick, M.E. Salama, S.D. Mendenhall, L.A. Moran, J.P. Agarwal, Side-to-side nerve bridges reduce muscle atrophy after peripheral nerve injury in a rodent model, J. Surg. Res. 187 (2014) 350-358.

[17] I.A. Thomazini-Santos, S.R.C.S. Barraviera, M.J.S. Mendes-Giannini, B. Barraviera, Surgical adhesives, J. Venom. Anim. Toxins. 7 (2001) 159-171.

[18] L.C. Barros, R.S. Ferreira Jr., S.R. Barraviera, H.O. Stolf, I.A. Thomazini-Santos, M.J. Mendes-Giannini, et al., A new fibrin sealant from Crotalus durissus terrificus venom: applications in medicine, J. Toxicol. Environ. Health B Crit. Rev. 12 (2009) 553-571.

[19] R. Barbizan, M.V. Castro, A.C. Rodrigues, B. Barraviera, R.S. Ferreira, A.L. Oliveira, Motor recovery and synaptic preservation after ventral root avulsion and repair with a fibrin sealant derived from snake venom, PLoS One 8 (2013) e63260.

[20] S.U. Benitez, R. Barbizan, A.B. Spejo, R.S. Ferreira Jr., B. Barraviera, A.M. Góes, et al., Synaptic plasticity and sensory-motor improvement following fibrin sealant dorsal root reimplantation and mononuclear cell therapy, Front. Neuroanat. 9 (2014) 8-96.

[21] V.P. Gasparotto, F.C. Landim-Alvarenga, A.L. Oliveira, G.F. Simões, J.F. Lima-Neto, B. Barraviera, et al., A new fibrin sealant as a three-dimensional scaffold candidate for mesenchymal stem cells, Stem Cell Res Ther 5 (2014) 78.

[22] R. Seabra Ferreira Jr., Autologous or heterologous fibrin sealant scaffold: which is the better choice? J. Venomous Anim. Toxins Incl. Trop. Dis. 18 (2014) 31.

[23] R.L. Buchaim, J.C. Andreo, B. Barraviera, R.S. Ferreira Junior, D.V. Buchaim, G.M. Rosa Junior, et al., Injury. Effect of low-level laser therapy (LLLT) on peripheral nerve regeneration using fibrin glue derived from snake venom, Injury 46 (2015) 655-660.

[24] C.N. de Barros, A.L. Miluzzi Yamada, R.S. Junior, B. Barraviera, C.A. Hussni, J.B. de Souza, et al., A new heterologous fibrin sealant as a scaffold to cartilage repairexperimental study and preliminary results, Exp. Biol. Med. (Maywood). 241 (2016) 1410-1415.

[25] E.G. Machado, J.P. Issa, F.A. Figueiredo, G.R. Santos, E.A. Galdeano, M.C. Alves, et al., A new heterologous fibrin sealant as scaffold to recombinant human bone morphogenetic protein-2 (rhBMP-2) and natural latex proteins for the repair of tibial bone defects, Acta Histochem. 117 (2015) 288-296.

[26] D.V. Buchaim, A.C. Rodrigues, R.L. Buchaim, B. Barraviera, R.S. Junior G.M. Junior, et al., The new heterologous fibrin sealant in combination with lowlevel laser therapy (LLLT) in the repair of the buccal branch of the facial nerve, Lasers Med. Sci. 31 (2016) 965-972.

[27] A. Gupta, P. Avci, M. Sadasivam, R. Chandran, N. Parizotto, D. Vecchio, et al., Shining light on nanotechnology to help repair and regeneration, Biotechnol. Adv. 31 (2013) 607-631.

[28] K.T. Pomini, J.C. Andreo, A.C. Rodrigues, J.B.O. Gonçalves, L.R. Daré, I.J. German, et al., Effect of low-intensity pulsed ultrasound on bone regeneration: biochemical and radiologic analyses, J. Ultrasound Med. 33 (2014) 713-717.

[29] V. Cury, A.I. Moretti, L. Assis, P. Bossini, S. Crusca Jde, C.B. Neto, et al., Parizotto. Low level laser therapy increases angiogenesis in a model of ischemic skin flap in rats mediated by VEGF, HIF-1 $\alpha$ and MMP-2, J. Photochem. Photobiol. B 125 (2015) 164-170.

[30] C. Ferraresi, N.A. Parizotto, M.V. Pires de Sousa, B. Kaippert, Y.Y. Huang, T. Koiso, et al., Light-emitting diode therapy in exercise-trained mice increases muscle performance, cytochrome c oxidase activity, ATP and cell proliferation, J. Biophotonics 9 (2016) 976.

[31] A. Gupta, G.K. Keshri, A. Yadav, S. Gola, S. Chauhan, A.K. Salhan, et al., Superpulsed (Ga-As, $904 \mathrm{~nm}$ ) low-level laser therapy (LLLT) attenuates inflammatory response and enhances healing of burn wounds, J. Biophotonics 8 (2015) 489-501.

[32] W. Xuan, T. Agrawal, L. Huang, G.K. Gupta, M.R. Hamblin, Low-level laser therapy for traumatic brain injury in mice increases brain derived neurotrophic factor (BDNF) and synaptogenesis, J. Biophotonics 8 (2015) 502-511.

[33] H. Abrahamse, Regenerative medicine, stem cells, and low-level laser therapy: future directives, Photomed. Laser Surg. 30 (2012) 681-682.

[34] R. Fekrazad, M. Sadeghi Ghuchani, M.B. Eslaminejad, L. Taghiyar, K.A. Kalhori, M.S. Pedram, et al., The effects of combined low level laser therapy and mesenchymal stem cells on bone regeneration in rabbit calvarial defects, J. Photochem. Photobiol. B 151 (2015) 180-185.

[35] N. Lane, Cell biology: power games, Nature 26 (2006) 901-903.

[36] A.C. Chen, P.R. Arany, Y.Y. Huang, E.M. Tomkinson, S.K. Sharma, G.B. Kharkwal, et al., Low-level laser therapy activates NF-kB via generation of reactive oxygen species in mouse embryonic fibroblasts, PLoS One 6 (2011) e22453.

[37] Y. Mikhed, A. Gorlach, U.G. Knaus, A. Daiber, Redox regulation of genome stability by effects on gene expression, epigenetic pathways and DNA damage/repair, Redox Biol. 5 (2015) 275-289.

[38] L. Luo, Z. Sun, L. Zhang, X. Li, Y. Dong, T.C. Liu, Effects of low-level laser therapy on ROS homeostasis and expression of IGF-1 and TGF- $\beta 1$ in skeletal muscle during the repair process, Lasers Med. Sci. 28 (2013) 725-734.

[39] I. Garavello-Freitas, V. Baranauskas, P.P. Joazeiro, C.R. Padovani, M. Dal Pai-Silva, M.A. da Cruz-Höfling, Low-power laser irradiation improves histomorphometrical parameters and bone matrix organization during tibia wound healing in rats, J. Photochem. Photobiol. B 70 (2003) 81-89.

[40] V. Cury, A.L. Moretti, L. Assis, P. Bossini, J.S. Crusca, C.B. Neto, et al., Low level laser therapy increases angiogenesis in a model of ischemic skin flap in rats mediated by VEGF, HIF-1 $\alpha$ and MMP-2, J. Photochem. Photobiol. B 5 (2013) $164-170$.

[41] R.S. Ferreira Jr., L.C. de Barros, L.P.F. Abbade, S.R.C.S. Barraviera, M.R.C. Silvares, L.G. de Pontes, et al., Heterologous fibrin sealant derived from snake venom: from 
bench to bedside - an overview, J. Venomous Anim. Toxins Incl. Trop. Dis, 23 (2017) 21.

[42] S.D. de Faria, J.R. Testa, A. Borin, R.N. Toledo, Standardization of techniques used in facial nerve section and facial movement evaluation in rats, Braz. J. Otorhinolaryngol. 72 (2006) 341-347.

[43] M.V. Ganga, J. Coutinho-Netto, B.O. Colli, W. Marques Junior, C.H. Catalão, R.T. Santana, et al., Sciatic nerve regeneration in rats by a nerve conduit engineering with a membrane derived from natural latex, Acta Cir. Bras. 27 (2012) 885-891.

[44] M.J. Brenner, A. Moradzadeh, T.M. Myckatyn, T.H. Tung, A.B. Mendez, D.A. Hunter, et al., Role of timing in assessment of nerve regeneration, Microsurgery 28 (2008) 265-272.

[45] T.Y. Farrag, M. Lehar, P. Verhaegen, K.A. Carson, P.J. Byrne, Effect of platelet rich plasma and fibrin sealant on facial nerve regeneration in a rat model, Laryngoscope 117 (2007) 157-165.

[46] M. Okochi, K. Ueda, H. Okochi, E. Asai, T. Sakaba, A. Kajikawa, Facial reanimation using hypoglossal-facial neurorrhaphy with end-to-side coaptation between the jump interpositional nerve graft and hypoglossal nerve: outcome and duration of preoperative paralysis, Microsurgery 36 (2016) 460-466.

[47] P. Tos, G. Colzani, D. Ciclamini, P. Titolo, P. Pugliese, S. Artiaco, Clinical applications of end-to-side neurorrhaphy: an update, Biomed. Res. Int. (2014) 646128.

[48] C.J. Knox, M.H. Hohman, I.J. Kleiss, J.S. Weinberg, J.T. Heaton, T.A. Hadlock, Facial nerve repair: fibrin adhesive coaptation versus epineurial suture repair in a rodent model, Laryngoscope 123 (2013) 1618-1621.

[49] T. Waitayawinyu, D.M. Parisi, B. Miller, S. Luria, H.J. Morton, S.H. Chin, et al., A comparison of polyglycolic acid versus type 1 collagen bioabsorbable nerve conduits in a rat model: an alternative to autografting, J. Hand. Surg. [Am.] 32 (2007) $1521-1529$.

[50] A.C. Moore, T.E. Mark, A.K. Hogan, J. Topczewski, E.E. LeClair, Peripheral axons of the adult zebrafish maxillary barbel extensively remyelinate during sensory appendage regeneration, J. Comp. Neurol. 520 (2012) 4184-4203.

[51] A.M. Marcolino, R.I. Barbosa, L.M.S. Neves, T.S. Vinas, D.T.S. Duarte, N. Mazzer, Low intensity laser $(830 \mathrm{~nm})$ functional to recover of the sciatic nerve in rats, Acta Ortop. Bras. 18 (2010) 207-211.

[52] T. Akgul, M. Gulsoy, H.O. Gulcur, Effects of early and delayed laser application on nerve regeneration, Lasers Med. Sci. 29 (2014) 351-357.

[53] Y.J. Chen, Y.H. Wang, C.Z. Wang, M.L. Ho, P.L. Kuo, M.H. Huang, et al., Effect of low level laser therapy on chronic compression of the dorsal root ganglion, PLoS One 9 (3) (2014 Mar 4) e8989e4.

[54] R.D. Lins, E.M. Dantas, K.C. Lucena, M.H. Catão, A.F. Granville-Garcia, L.G. Carvalho Neto, Biostimulation effects of low-power laser in the repair process, An. Bras. Dermatol. 85 (2010) 849-855.

[55] M.J. Nagata, C.S. Santinoni, N.M. Pola, N. de Campos, M.R. Messora, S.R. Bomfim, et al., Bone marrow aspirate combined with low-level laser therapy: a new therapeutic approach to enhance bone healing, J. Photochem. Photobiol. B 121 (2013) $6-14$.

[56] M. Ochi, M. Noda, K. Nakamitsu, M. Deie, Y. Ikuta, Y. Maki, Promotion of sciatic nerve regeneration in rats by a new neurotrophic pyrimidine derivative MS-430, Gen. Pharmacol. 26 (1995) 59-64.

[57] C. Endo, C.H. Barbieri, N. Mazzer, V.S. Fasan, Low-power laser therapy accelerates peripheral nerves' regeneration, Acta Ortop. Bras. 16 (2008) 305-310.

[58] R.I. Barbosa, A.M. Marcolino, R.R. de Jesus Guirro, N. Mazzer, C.H. Barbieri, M. de Cássia Registro Fonseca, Comparative effects of wavelengths of low-power laser in regeneration of sciatic nerve in rats following crushing lesion, Lasers Med. Sci. 25 (2010) 423-430.

[59] C.N. Câmara, M.V. Brito, E.L. Silveira, D.S. Silva, V.R. Simões, R.W. Pontes, Histological analysis of low-intensity laser therapy effects in peripheral nerve regeneration in Wistar rats, Acta Cir. Bras. 26 (2011) 12-18.
[60] B.F. Trawitzki, L. Lilge, F.A.T de Figueiredo, A.P. Macedo, J.P.M. Issa, Low-intensity laser therapy efficacy evaluation in mice subjected to acute arthritis condition, J. Photochem. Photobiol. B. 174 (2017) 126-132.

[61] C.C. Alcântara, D. Gigo-Benato, T.F. Salvini, A.L. Oliveira, J.J. Anders, T.L. Russo, Effect of low-level laser therapy (LLLT) on acute neural recovery and inflammation related gene expression after crush injury in rat sciatic nerve, Lasers Surg. Med. 45 (2013) 246-252.

[62] F.R. Guerra, C.P. Vieira, M. dos Santos de Almeida, L.P. Oliveira, A.C. Claro, G.F. Simões, Pulsed LLLT improves tendon healing in rats: a biochemical, organizational, and functional evaluation, Lasers Med. Sci. 29 (2014) 805-811.

[63] D.V. Buchaim, J.C. Andreo, R.S. Ferreira Junior, B. Barraviera, A.C. Rodrigues, M.C. Macedo, et al., Efficacy of laser photobiomodulation on morphological and functional repair of the facial nerve, Photomed. Laser Surg. 35 (2017) 442-449.

[64] D. Barolet, P. Duplay, H. Jacomy, M. Auclair, Importance of pulsing illumination parameters in low-level-light therapy, J. Biomed. Opt. 15 (2010) 048005.

[65] C. Veronesi, E. Maggiolini, G. Franchi, Postnatal development of vibrissae motor output following neonatal infraorbital nerve manipulation, Exp. Neurol. 200 (2006) $332-342$

[66] G.M. Melo, O. Cervantes, L. Covolan, H.A. Baptista, E.S. Ferreira, M. Abrahao, Facial nerve identification with fluorescent dye in rats, Acta Cir. Bras. 31 (2016) 92-102.

[67] W. Sun, W. Feng, H. Lu, S. Gong, Synaptic plasticity in the facial nucleus in rats following infraorbital nerve manipulation after facial nerve injury, Eur. Arch. Otorhinolaryngol. 273 (2016) 3135-3142.

[68] C.C. Medalha, A.L. Santos, S.O. Veronez, K.R. Fernandes, A.M. Magri, A.C. Renno, Low level laser therapy accelerates bone healing in spinal cord injured rats, J. Photochem. Photobiol. B 159 (2016) 179-185.

[69] P.S. Bossini, R. Fangel, R.M. Habenschus, A.C. Renno, B. Benze, J.A. Zuanon, et al., Low-level laser therapy $(670 \mathrm{~nm})$ on viability of random skin flap in rats, Lasers Med. Sci. 24 (2009) 209-213.

[70] M.S. Moreira, I.T. Velasco, L.S. Ferreira, S.K. Ariga, D.F. Barbeiro, D.T. Meneguzzo, et al., Effect of phototherapy with low intensity laser on local and systemic immunomodulation following focal brain damage in rat, J. Photochem. Photobiol. B 97 (2009) 145-151.

[71] D. Gigo-Benato, S. Geuna, S. Rochkind, Phototherapy for enhancing peripheral nerve repair: a review of the literature, Muscle Nerve 31 (2005) 694-701.

[72] D. Gigo-Benato, S. Geuna, A. de Castro Rodrigues, P. Tos, M. Fornaro, E. Boux, et al., Low-power laser biostimulation enhances nerve repair after end-to-side neurorrhaphy: a double-blind randomized study in the rat median nerve model, Lasers Med. Sci. 19 (2004) 57-65.

[73] S.M. Khullar, P. Brodin, E.B. Messelt, H.R. Haanaes, The effects of low level laser treatment on recovery of nerve conduction and motor function after compression injury in the rat sciatic nerve, Eur. J. Oral Sci. 103 (1995) 299-305.

[74] M. Miloro, L.E. Halkias, S. Mallery, S. Travers, R.G. Rashid, Low-level laser effect on neural regeneration in Gore-Tex tubes, Oral Surg. Oral Med. Oral Pathol. Oral Radiol. Endod. 93 (2002) 27-34.

[75] J.B. Oliveira Gonçalves, D.V. Buchaim, C.R. de Souza Bueno, K.T. Pomini, B. Barraviera, R.S. Júnior, et al., Effects of low-level laser therapy on autogenous bone graft stabilized with a new heterologous fibrin sealant, J. Photochem. Photobiol. B 162 (2016) 663-668.

[76] C.C. Medalha, G.C. Di Gangi, C.B. Barbosa, M. Fernandes, O. Aguiar, et al., Lowlevel laser therapy improves repair following complete resection of the sciatic nerve in rats, Lasers Med. Sci. 27 (2012) 629-635.

[77] C.M. Fiacconi, A.M. Owen, Using facial electromyography to detect preserved emotional processing in disorders of consciousness: a proof-of-principle study, Clin. Neurophysiol. 127 (2016) 3000-3006.

[78] S.R. Tsai, M.R. Hamblin, Biological effects and medical applications of infrared radiation, J. Photochem. Photobiol. B 170 (2017) 197-207. 